\title{
Efficacy of laser monotherapy or non-surgical mechanical instrumentation in the management of untreated periodontitis patients. A systematic review and meta-analysis
}

\author{
Zhikai Lin $^{1,2} \cdot$ Franz J. Strauss ${ }^{3,4} \cdot$ Niklaus P. Lang ${ }^{1} \cdot$ Anton Sculean $^{1} \cdot$ Giovanni E. Salvi ${ }^{1} \cdot$ Alexandra Stähli $^{1}$
}

Received: 2 August 2020 / Accepted: 11 September 2020 / Published online: 10 November 2020

(C) The Author(s) 2020

\begin{abstract}
Objective To evaluate and compare the effects of laser monotherapy with non-surgical mechanical instrumentation alone in untreated periodontitis patients.

Materials and methods A focused question was formulated based on the Population, Intervention, Comparison, Outcome, and Study design criteria (PICOS): in patients with untreated periodontitis, does laser mono-therapy provide adjunctive effects on pocket probing depth (PPD) changes compared with non-surgical instrumentation alone? Both randomized controlled clinical trials (RCTs) and controlled clinical trials (CCTs) were included. The results of the meta-analyses are expressed as weighted mean differences (WMD) and reported according to the PRISMA guidelines.

Results The search yielded 1268 records, out of which 8 articles could be included. With respect to PPD changes, a meta-analysis including 5 articles $(n=148)$ failed to identify statistically significant differences in favor of laser monotherapy for PPD change $(\mathrm{WMD}=0.14 \mathrm{~mm} ; 95 \% \mathrm{CI}:-0.04 / 0.32 ; z=1.51 ; p=0.132)$ nor for clinical attachment level (CAL) $(\mathrm{WMD}=0.04 \mathrm{~mm} ; 95 \% \mathrm{CI}$ : $-0.35 / 0.42 ; z=0.19 ; p=0.850$ ). Data on cost-effectiveness are lacking. One study reported patient-related outcome measures (PROMS).

Conclusions In untreated periodontitis patients, laser monotherapy does not yield superior clinical benefits compared with nonsurgical mechanical instrumentation alone.

Clinical relevance In untreated periodontitis patients, mechanical instrumentation with hand and/or ultrasonic instruments remains the standard of care.
\end{abstract}

Keywords Periodontitis $\cdot$ Laser $\cdot$ Laser monotherapy $\cdot$ Monotherapy $\cdot$ Non-surgical periodontal treatment $\cdot$ Systematic review

\section{Introduction}

Bacterial hard and soft deposits constitute the etiological agents in the initiation and progression of periodontitis [1].

Alexandra Stähli

alexandra.staehli@zmk.unibe.ch

1 Department of Periodontology, School of Dental Medicine, University of Bern, Freiburgstrasse 7, 3010 Bern, Switzerland

2 Department of Periodontology, Ninth People's Hospital, Shanghai JiaoTong University School of Medicine, Shanghai, China

3 Clinic of Reconstructive Dentistry, Center of Dental Medicine, University of Zurich, Zurich, Switzerland

4 Department of Conservative Dentistry Faculty of Dentistry, University of Chile, Santiago, Chile
Non-surgical mechanical instrumentation aims at removing the microbial biofilm and calcified deposits and to prepare a biologically acceptable surface that allows healing and regeneration $[2,3]$. Subgingival calculus removal by hand and/or power-driven instruments is considered the standard of care [4]; it can, however, lead to excessive cementum removal [5], the creation of grooves, or leave calculus remnants. Anatomical critical sites often limit access to hand instruments. Furthermore, mechanical debridement results in a smear layer [6] containing bacteria, endotoxins, and contaminated cementum. Lasers have been incorporated in the treatment of periodontitis to reduce bacterial infection and bleeding, to improve access for complex anatomical structures, and to increase patient comfort and possibly stimulate the healing process. When using laser irradiation instead of mechanical non-surgical instrumentation, appropriate lasers that are able to remove plaque deposits and calculus have to be used. 
The first use of a ruby laser for calculus removal was presented in 1965 [7]. The Nd:YAG laser, approved for hard tissues in 1999, was initially propagated for calculus removal. However, the wavelength of $1064 \mathrm{~nm}$ is mostly absorbed in dark tissues, and high irradiation output to remove calculus has been shown to cause thermal damage, such as carbonization [8] and chemical alterations of root proteins [9]. Of the lasers used in dentistry, the ER:YAG laser is largely absorbed in water with an absorbance 10 times higher than that of $\mathrm{CO}_{2}$ laser and 15000 to 20000 times higher than the one of $\mathrm{Nd}: Y A G$ laser [10]. Ablation of both hard and soft tissues is possible, and due to its high absorption in water, Er:YAG lasers cause less damage to hard tissues containing small amounts of water [11-13]. Er:YAG lasers contain a yttrium aluminum garnet (YAG) crystal doped with erbium ions which generate a wavelength of $2936 \mathrm{~nm}$. Wavelength is a major factor in the absorption of laser light by different biologic tissues. The laser light that is produced can be converted into kinetic energy in the form of shock waves, which then destroy the target tissue, in this case, calculus [14]. These shock waves are formed as a result of volumetric expansion which occurs when water evaporates. The calculus ablation primarily occurs through the evaporation of the water within the hard tissue itself. The resulting shock waves propagate through the calculus, spalling it from the underlying tissuea process called laser spallation. Calculus contains a large volume of water and therefore absorbs the emission wavelength to a large extent. Secondly, the irrigation water serves as another evaporative medium where the explosive force of the vaporization of the thin film of water is transferred to the hard tissue, thus removing it [15]. These two effects combined increase the efficiency of the removal of the target tissue.

Recent systematic reviews have thoroughly documented the use of Er:YAG laser in non-surgical periodontal therapy [16]. It was reported that Er:YAG and Er,Cr:YSGG are able to sufficiently remove subgingival calculus. In a histologic study, the Er:YAG laser achieved plaque and calculus removal similar to hand instrumentation though leaving a rough surface morphology [17]. Similarly, the Er:YAG laser in vitro displayed increased loss of cementum and dentin [18] along with superficial thermal micro-changes compared with conventional scaling procedures [19]. Laser scaling further necessitated more time than ultrasonic scaling [19].

Despite reports of positive outcomes on the use of Er:YAG lasers in the management of untreated periodontitis, clinically relevant benefits for the patient need to be systematically appraised. Outcomes of a recent systematic review by our group focused on the combined nonsurgical therapy with laser and mechanical instrumentation and failed to indicate adjunctive benefits of laser application in the management of untreated periodontitis when compared with non-surgical mechanical instrumentation alone [20]. However, the potential benefits of laser monotherapy in the management of untreated periodontitis remain to be investigated. Therefore, the aim of the present systematic review was to assess and compare the effectiveness of laser monotherapy with that of non-surgical mechanical instrumentation alone in patients with untreated periodontitis.

\section{Material and methods}

\section{Study registration}

The protocol of this review was registered in the PROSPERO international prospective register of systematic reviews hosted by the National Institute for Health Research (NIHR), University of York, UK, Center for Reviews and Dissemination. The allocated number is CRD42020182626.

\section{Reporting format}

The Preferred Reporting Items for Systematic Reviews and Meta-analyses were adopted throughout the process of the present systematic review [21-23].

\section{Population, Intervention, Comparison, Outcomes, and Study design}

Population Patients with untreated periodontitis

Intervention Laser application alone

Comparison Non-surgical mechanical instrumentation by means of hand and/or power-driven instrumentation alone

\section{Outcome measures}

Primary outcome Change in pocket probing depths (PPD)

Secondary outcomes Change in clinical attachment levels [24] (CAL)

Residual PPD

Change in Bleeding on Probing (BoP)

Change in plaque index (PII)

Change in gingival crevicular fluid (GCF) biomarker levels Microbiological change in subgingival plaque

Patient-reported outcome measures (PROMs)

Study design The following study designs were considered:

- Randomized controlled clinical trials (RCTs)

- Prospective placebo-controlled clinical trials (CCTs)

- Studies with split-mouth and parallel-arm design 


\section{Focused question}

The following focused question was adapted using the Population, Intervention, Comparison, Outcomes, and Study design (PICOS) criteria [25]:

In patients with untreated periodontitis, how does laser monotherapy compare with non-surgical mechanical instrumentation alone in terms of PPD changes?

\section{Search strategy}

\section{Electronic search}

A comprehensive and systematic electronic search of MEDLINE via PubMed, Scopus, and Cochrane Central Register of Controlled Trials (CENTRAL) databases was conducted for studies in humans published in English up to February 29, 2020. Language was limited to English.

The following search terms were used:

PubMed search terms For the search in the PubMed library, combinations of controlled terms (MeSH) and keywords were used whenever possible:

("periodontal diseases" [MeSH Terms] OR "periodontitis" [MeSH Terms]) AND ("laser" [All Fields]) AND ("non-surgical" [All Fields] OR "non surgical" [All Fields] OR "scaling" [All Fields] OR "root planing"[All Fields] OR "root planning"[All Fields] or "debridement"[All Fields] OR "conventional periodontal therapy" [All Fields])

Scopus search terms (KEY ("periodontal diseases" OR "periodontitis")) AND (TITLE-ABS-KEY ("laser")) AND (TITLE-ABS-KEY ("non-surgical” OR "non-surgical” OR "scaling" OR "root planing" OR "root planning" OR "debridement" OR "conventional periodontal therapy"))

Cochrane database for randomized controlled trials search terms (MeSH descriptor: [Periodontitis] explode all trees OR MeSH descriptor: [Periodontal Diseases] explode all trees) AND (All text ("laser")) AND (All text ("non-surgical" OR "non-surgical" OR "scaling" OR "root planing" OR "root planning" OR "debridement" OR "conventional periodontal therapy"))

\section{Manual search}

A manual search of the reference lists of relevant reviews and systematic reviews on the topics as well as of the reference lists of the included full-text articles was performed.

\section{Inclusion criteria}

The inclusion criteria were:
- Laser therapy alone as one of the treatment groups and non-surgical mechanical instrumentation as control group.

- Follow-up of at least 6 months with clinical examination.

- At least 20 patients per treatment arm at 6-month follow-up.

- At least 20 patients at 6-month follow-up for studies with split-mouth design.

- Non-surgical instrumentation by means of hand and/or power-driven instruments.

- For meta-analyses: RCTs/CCTs reporting a single session of non-surgical mechanical instrumentation alone or laser monotherapy and PPD/CAL changes at the 6-month follow-up.

\section{Exclusion criteria}

The exclusion criteria were:

- Studies including patients with treated periodontitis or in the course of supportive periodontal therapy (SPT) or referred patients with pre-treated periodontitis.

- Studies including a combination of laser and SPT or laser as adjunctive therapy.

- Abstracts

- Letters to editors

- Narrative reviews

- Case reports or case series

- Insufficient/unclear information not allowing data extraction

- No author response to inquiry e-mail for data clarification

\section{Screening}

Literature screening was performed independently by two reviewers (A.S. and Z.L.). Discrepancies were solved by discussion among authors. Cohen's Kappa score was calculated to measure the agreement between the reviewing authors. The reviewers independently performed the search and screening process.

\section{Data extraction}

Data addressing the primary and secondary outcome measures were extracted in duplicate by two independent reviewers (Z.L. and A.S.) for qualitative and quantitative analysis from the selected articles fulfilling the inclusion criteria.

\section{Quality assessment}

The criteria used to evaluate the quality of the selected controlled trials were adopted from the checklist of the Cochrane Center and the CONSORT (Consolidated Standards of 
Reporting Trials) statement, providing guidelines for the following parameters: (a) sequence generation; (b) allocation concealment method; (c) masking of the examiner; (d) address of incomplete outcome data; and (e) free of selective outcome reporting.

The degree of bias was categorized as low risk if all the criteria were met, moderate risk when only one criterion was missing, and high risk if two or more criteria were missing. Potential impact of risk of bias for sample size calculation, patient selection, and reporting was considered for each selected study.

\section{Data analysis}

Changes in periodontal parameters between baseline and the follow-up period were calculated using the following formulae;

1 If PPD or CAL pre- and post-intervention mean difference was not directly reported in the studies, then it was calculated according to the following formula, $\triangle \mathrm{PD}=\mathrm{PD}_{2}-$ $\mathrm{PD}_{1}$, where $\triangle \mathrm{PD}$ stands for the reduction of probing depth; $\mathrm{PD}_{2}$ stands for the post-treatment probing depth value, while $\mathrm{PD}_{1}$ is the pre-treatment probing depth value.

2 If the standard deviation of the pre- and post-intervention mean difference was not reported in the studies, then it was calculated according to the following formula: $\mathrm{SD}=\sqrt{ }$ $\left(\mathrm{SD}_{1}^{2}+\mathrm{SD}_{2}^{2}-2 r \times \mathrm{SD}_{1} \times \mathrm{SD}_{2}\right)$; the coefficient $\mathrm{r}$ was calculated according to [26].

Results documenting PPD and CAL changes were extracted or calculated from RCTs and used to evaluate the effect of laser monotherapy compared with non-surgical mechanical instrumentation in patients with untreated periodontitis.

The results for continuous data such as changes in PPD (primary outcome) and CAL (secondary outcome) at the 6month follow-up were measured with weighted mean differences (WMD) and 95\% confidence intervals (CIs). A randomeffect model was used to calculate the pooled WMDs, and $z$ test was applied to determine the statistical significance for pooled WMDs. Forest plots were used to illustrate the outcomes of the meta-analyses. The statistical heterogeneity among studies was explored by the $I^{2}$ index [27]. If $I^{2}$ was found larger than $75 \%$, then the risk of heterogeneity was high.

Statistical significance was set to $p<0.05$.

\section{Results}

\section{Search}

A total of 1268 records were identified through the electronic search. After removal of 294 duplicates, 974 records remained for title and abstract screening. Based on abstract screening, another 939 articles were excluded. No citations from the manual search and the gray literature search were identified (Fig. 1).

A total of 35 articles remained for full-text evaluation. Following exclusion of 26 articles based on full-text analysis (Table 1), 8 articles remained to be included.

An inter-examiner Cohen's kappa score was calculated according to the results from title and abstract screening. The kappa score between the two examiners was 0.798 .

\section{Laser monotherapy}

\section{Description of included studies}

The characteristics of the 8 articles ( 7 studies) evaluating laser monotherapy are summarized in Table 2 [54-61].

\section{Study design}

Two articles included two experimental and two control groups $[58,59]$. One article included two experimental groups and one control group [61] while the remaining 5 articles included one experimental and one control group, respectively.

One article reported on a parallel arm design [61] while the remaining 7 articles reported on a split-mouth design. One article [55] published the 2-year follow-up data of a previous article [54]. Two articles reported 2-year follow-up data [55, 57] while the follow-up of the other 6 articles was 6 months.

The total number of patients treated was 209 of whom 149 were included in studies with a split-mouth and 60 in studies with a parallel arm design, respectively.

\section{Study samples}

Sample sizes of the included studies varied from 20 to 60 patients. The age of the included patients ranged from 28 to 79 years and the mean age from 41.8 to 53 years. The percentage of females ranged from 51.8 to $70.0 \%$ and of males from 30.0 to $48.9 \%$, respectively. Smokers were included in 2 studies [58, 59], excluded in another two studies [60, 61], whereas the remaining studies did not report on tobacco consumption. One study reported on patients diagnosed with aggressive periodontitis [58], and 6 studies on patients diagnosed with chronic periodontitis [54-57, 59-61].

All studies were performed in single centers. Only one study [58] was conducted in a private dental clinic while the remaining 6 studies were conducted in a university setting. 


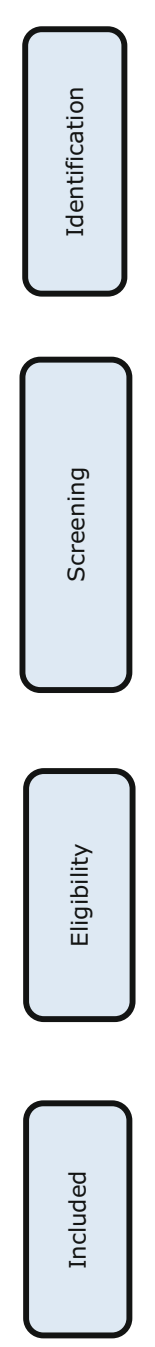

Records identified through other

sources

$n=520$ and Cochrane)

$n=748$

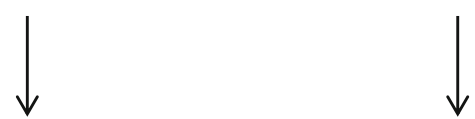

Records screened after duplicate

removal

$\mathrm{n}=974$
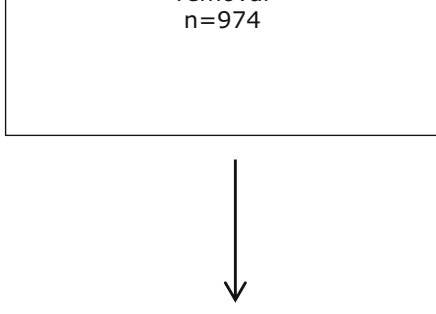
assessed for eligibility

$n=35$
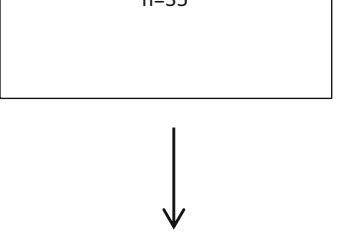

Articles included $n=8$

Fig. 1 PRISMA flow chart depicting the selection process

\section{Intervention/comparison}

Three different types of laser were used in the 7 included studies; 2 different kinds of lasers were used in one study [61]. Diode laser was used in 1 study [58], Er:YAG laser in 6 studies [54-57, 59-61], and Er:YAG laser and Nd:YAG laser in 1 study [61].

In all studies, non-surgical mechanical instrumentation and laser monotherapy were reported to be performed in one session except for the combined Er:YAG/Nd:YAG laser treatment group in one study [61]. In that group, two additional sessions of Nd:YAG treatments were applied after Er:YAG laser treatment. The physical parameters of the lasers are summarized in Table 2.

For non-surgical mechanical instrumentation, 3 studies reported using hand instruments only $[54,55,58,61]$ while 2 studies reported using power-driven devices only $[56,57]$ and 2 studies mentioned using a combination of hand instruments and power-driven devices $[59,60]$.
As far as the application of local anesthesia was concerned, 3 studies reported the use of local anesthesia [56, 58, 61], in 1 study local anesthesia was reported to be delivered if needed [59], and the remaining 2 studies did not provide any information related to the use of local anesthesia.

\section{Outcomes}

Clinical outcome parameters of the 8 articles ( 7 studies) evaluating laser as monotherapy are shown in Table 3. In order to perform meta-analyses on the primary (i.e., PPD change) and secondary outcome measure (i.e., CAL change), 5 articles including the 6-month PPD and CAL changes and reporting on non-surgical mechanical instrumentation or laser monotherapy in one session were selected [54, 56, 59-61].

Funnel plots are not reported to illustrate publication bias, based on the small number of studies in both meta-analyses (i.e., $<10$ ). 
Table 1 Studies excluded based on full-text analysis and reasons for exclusion

\begin{tabular}{ll}
\hline First author (year of publication) & Reason for exclusion \\
\hline Alzoman and Diab (2016) [28] & 1 \\
Ambrosini et al. (2005) [29] & 2 \\
Amid et al. (2017) [30] & 3 \\
Andersen et al. (2007) [31] & 3 \\
Badran et al. (2012) [32] & 1 \\
Bocher et al. (2019) [33] & 3 \\
Castro et al. (2019) [34] & 3 \\
Ciurescu et al. (2019) [35] & 3 \\
Derdilopoulou et al. (2007) [36] & 3 \\
Everett et al. (2017) [37] & 3 \\
Foroutan et al. (2013) [38] & 3 \\
Ge et al. (2017) [39] & 2 and 3 \\
Gianelli et al. (2012) [40] & 3 \\
Gomez et al. (2009) [41] & 3 \\
Harmouche et al. (2019) [42] & 3 \\
Jensen et al. (2010) [43] & 1 \\
Krohn-Dale et al. (2012) [44] & 1 \\
Lopes et al. (2008) [45] & 2 \\
Malali et al. (2012) [46] & 3 \\
Miyazaki et al. (2003) [47] & 3 \\
Moritz et al. (1997) [48] & 3 \\
Moritz et al. (1998) [49] & 3 \\
Noro Filho et al. (2012) [50] & 3 \\
Saglam et al. (2017) [51] & 3 \\
Soo et al. (2012) [52] & 3 \\
Yilmaz et al. (2002) [53] & 3 \\
\hline
\end{tabular}

1 , number of subjects $<20 ; 2$, follow-up time $<6$ months; 3 , study protocol does not match with stated focused question; 4 , endpoints do not match with stated inclusion criteria; 5, no data at 6-month follow-up; 6, other reasons (e.g., follow-up time unknown); *no author response to inquiry e-mail for data clarification

\section{Primary outcome: change in PPD}

Figure 2 shows the results of the meta-analysis for changes in PPD based on 5 studies evaluating 148 patients [54, 56, 59-61]. Two of 5 selected studies favored laser monotherapy $[61,54]$; meanwhile, the rest 3 studies demonstrated slightly better improvement in the control groups than in test groups. No statistically significant difference $(\mathrm{WMD}=0.14 \mathrm{~mm} ; 95 \%$ CI: $-0.04 / 0.32 ; z=1.51 ; p=0.132$ ) was found comparing the use of laser monotherapy with non-surgical mechanical instrumentation alone. The heterogeneity across the studies was low for PPD change $\left(I^{2}=36.7 \%\right)$.

Interestingly, PPD changes for sites with different initial PPD were compared between laser monotherapy and non- surgical mechanical instrumentation in 5 separate studies [54-57, 60, 61]. These studies grouped the sites with PPD of 5 and $6 \mathrm{~mm}$ and PPD of $7 \mathrm{~mm}$ or more as moderately deep sites and deep sites $[54,60]$, as shallow sites with $4-5 \mathrm{~mm}$ PPD and sites with $>5 \mathrm{~mm}$ PPDs [56] or as 4-6 $\mathrm{mm}$ and sites with $>6 \mathrm{~mm}$ [61]. At the 2-year follow-up, PPD showed more reduction in the Er:YAG laser group compared with the SRP group in both moderately deep and deep sites, respectively [55]. Furthermore, the difference was more significant in initially deep pockets than in shallow or moderate pockets.

\section{Secondary outcomes}

Figure 3 summarizes the results of the meta-analysis for changes in CAL based on 5 studies [54, 56, 59-61]. No statistically significant difference (WMD $=0.04 \mathrm{~mm} ; 95 \% \mathrm{CI}$ : $0.35 / 0.42 ; z=0.19 ; p=0.850$ ) was found comparing the use of laser monotherapy with non-surgical mechanical instrumentation alone. The heterogeneity across the studies was high for CAL change $\left(I^{2}=80.4 \%\right)$. Only one study favored the laser therapy [54], whereas the remaining 4 studies reported almost the same CAL gain between laser monotherapy and non-surgical mechanical instrumentation.

CAL changes within sites of different initial pocket depth were reported in 5 studies [54-57, 60, 61]. Two studies reported identical CAL changes for all of the sites between the two treatment modalities at the 6-month follow-up [56, 60]. While two studies with 2-year follow-up reported that initially deeper pockets $(\geq 7 \mathrm{~mm}$ ) showed the greatest changes in CAL, and moderately deep pockets exhibited moderate improvements, shallow sites $(<4 \mathrm{~mm})$ showed the least amount of changes $[55,57]$. In a more recent study, Grzech-Leśniak reported that both Er:YAG laser alone and in combination with Nd:YAG laser showed less CAL loss than the SRP group in shallow periodontal pockets $<4 \mathrm{~mm}$, but all treatments reduced PPD and CAL significantly without differences between treatment modalities in deep periodontal pockets at 6 months [61]. For the moderately deep pockets, Er:YAG alone and SRP exhibited no statistically difference in CAL change, while the combined Nd:YAG and Er:YAG laser group significantly gained CAL.

Table 4 summarizes the studies reporting on all selected outcomes. A total of 6 studies reported residual PPD, 3 of them detected the statistical difference between laser monotherapy and SRP. Two studies reported less residual PPD in laser group at both 1 and 2-year follow-up [55, 57], whereas one study found more residual PPD for initial shallow pockets in laser monotherapy compared with non-surgical mechanical instrumentation at 6-month follow-up [60, 62]. All the studies reported BoP/BI and PI/PII; however, 2 articles found statistically significant $\mathrm{BoP}$ changes and only 1 study found statistically significant PII changes between test and control group at 6 months. Mean change in PROMS [59] and GCF 


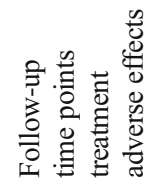
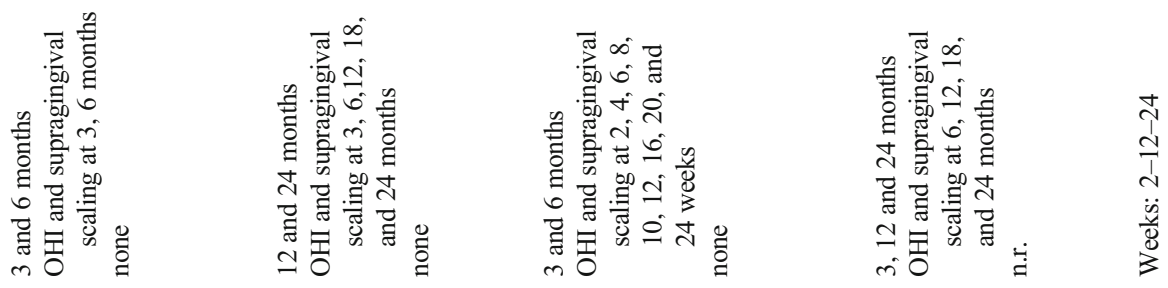

节
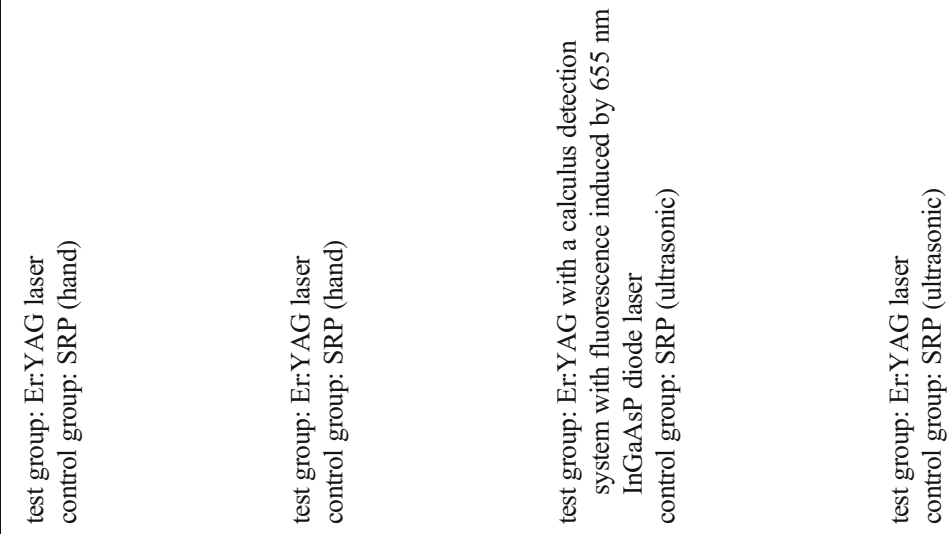

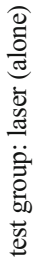

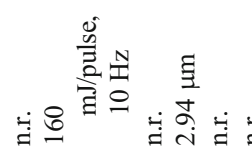

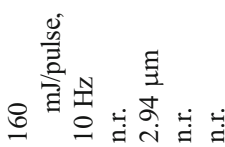

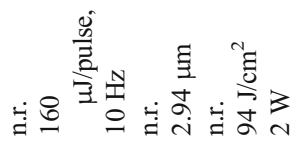

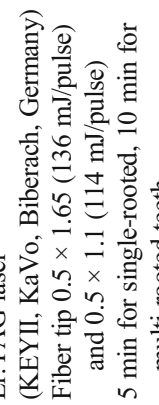

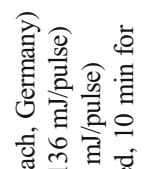

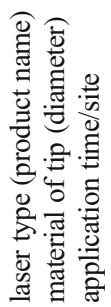

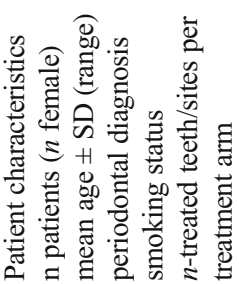

胥

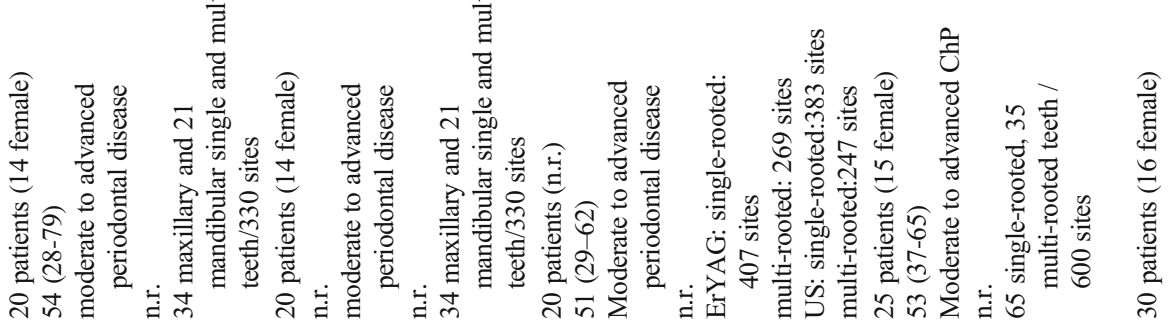

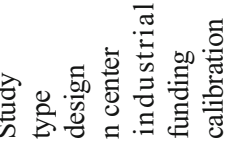

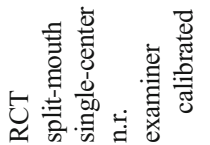

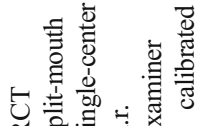

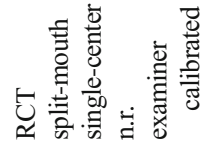

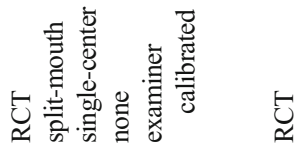

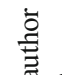

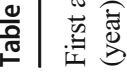

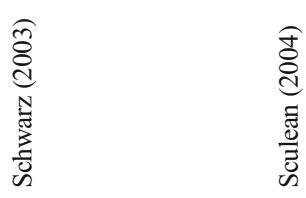

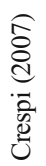

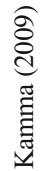




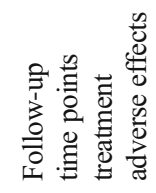

䔍

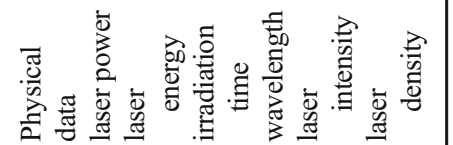

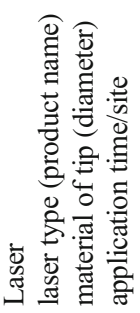
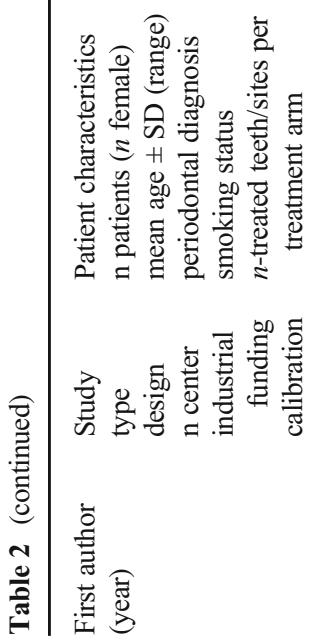

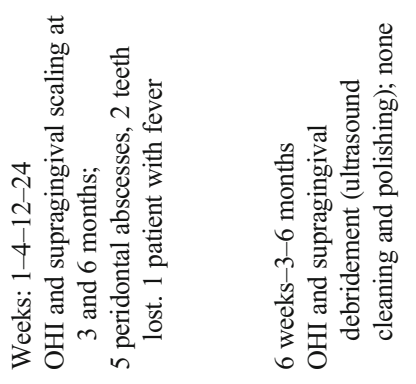

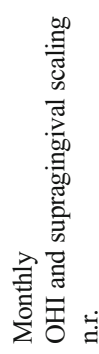
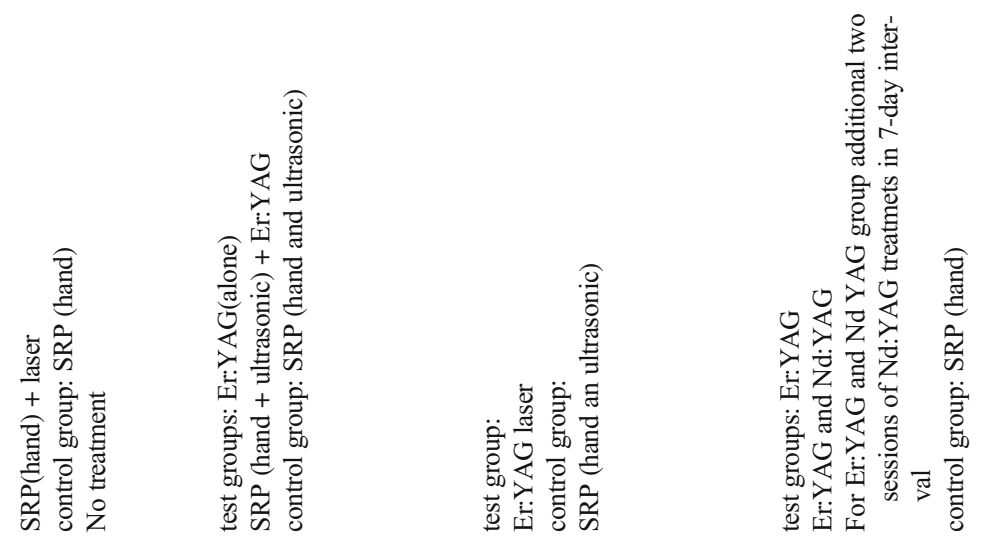

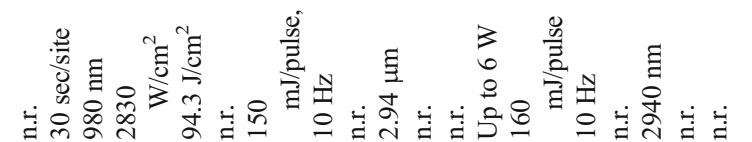

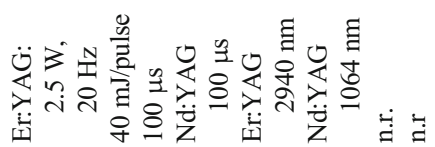

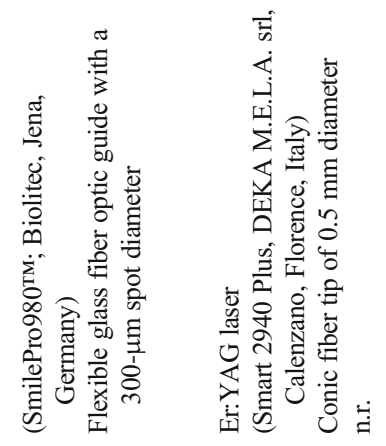

0

总

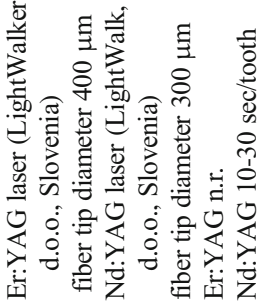

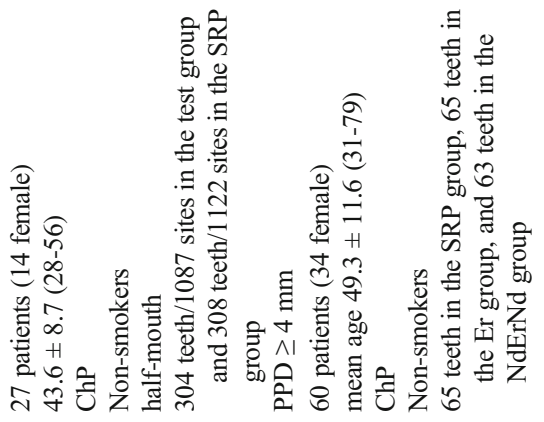

:

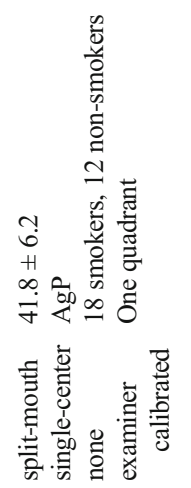

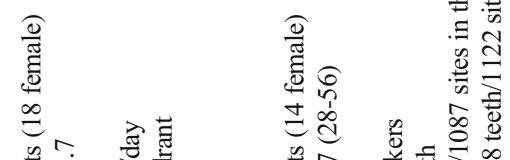

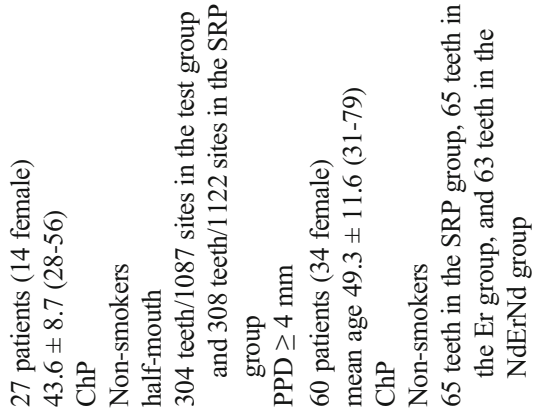

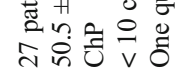

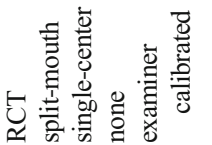

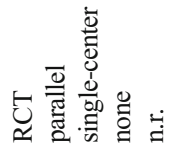

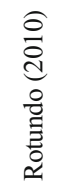

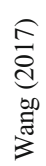

惫 


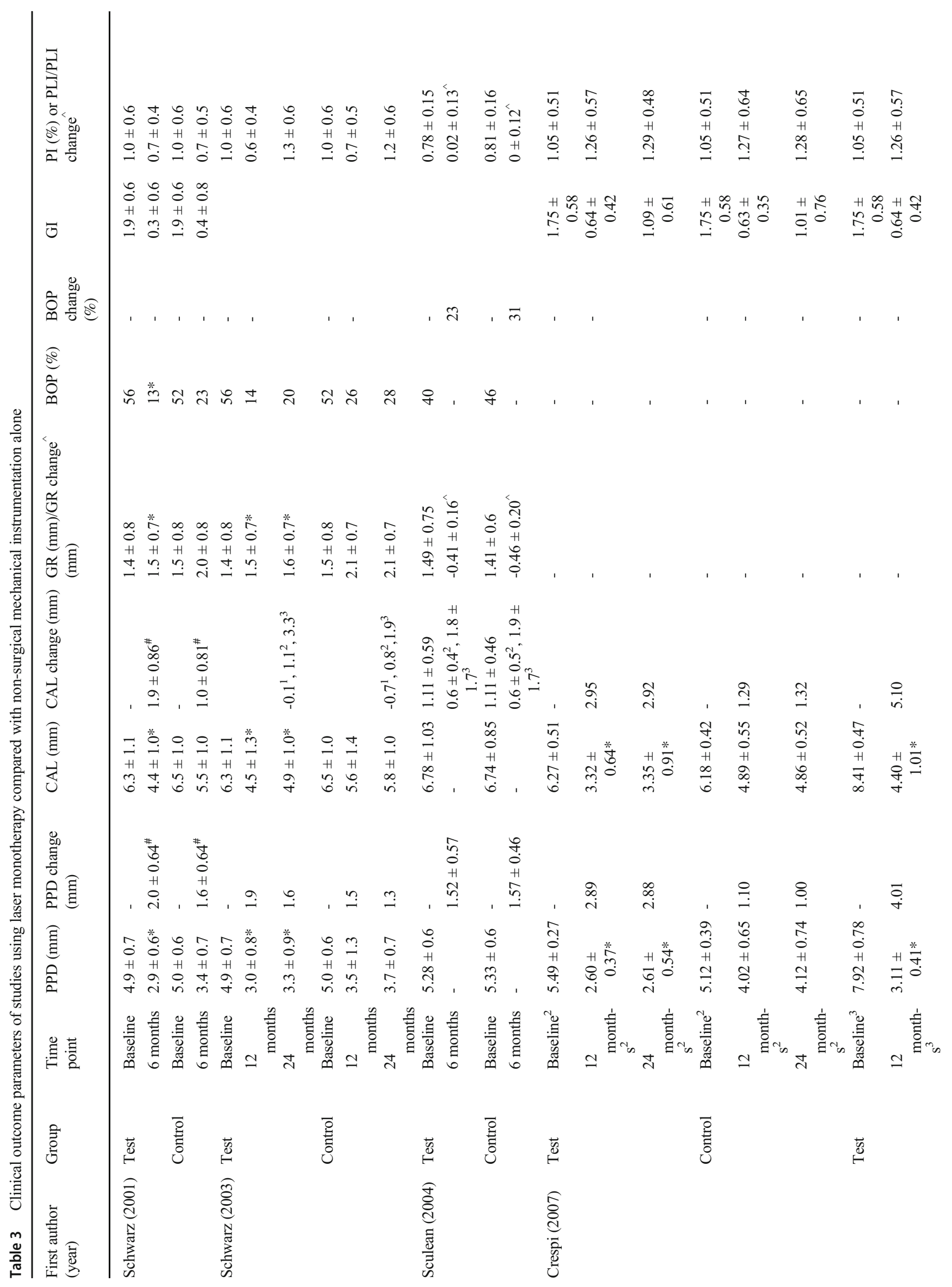




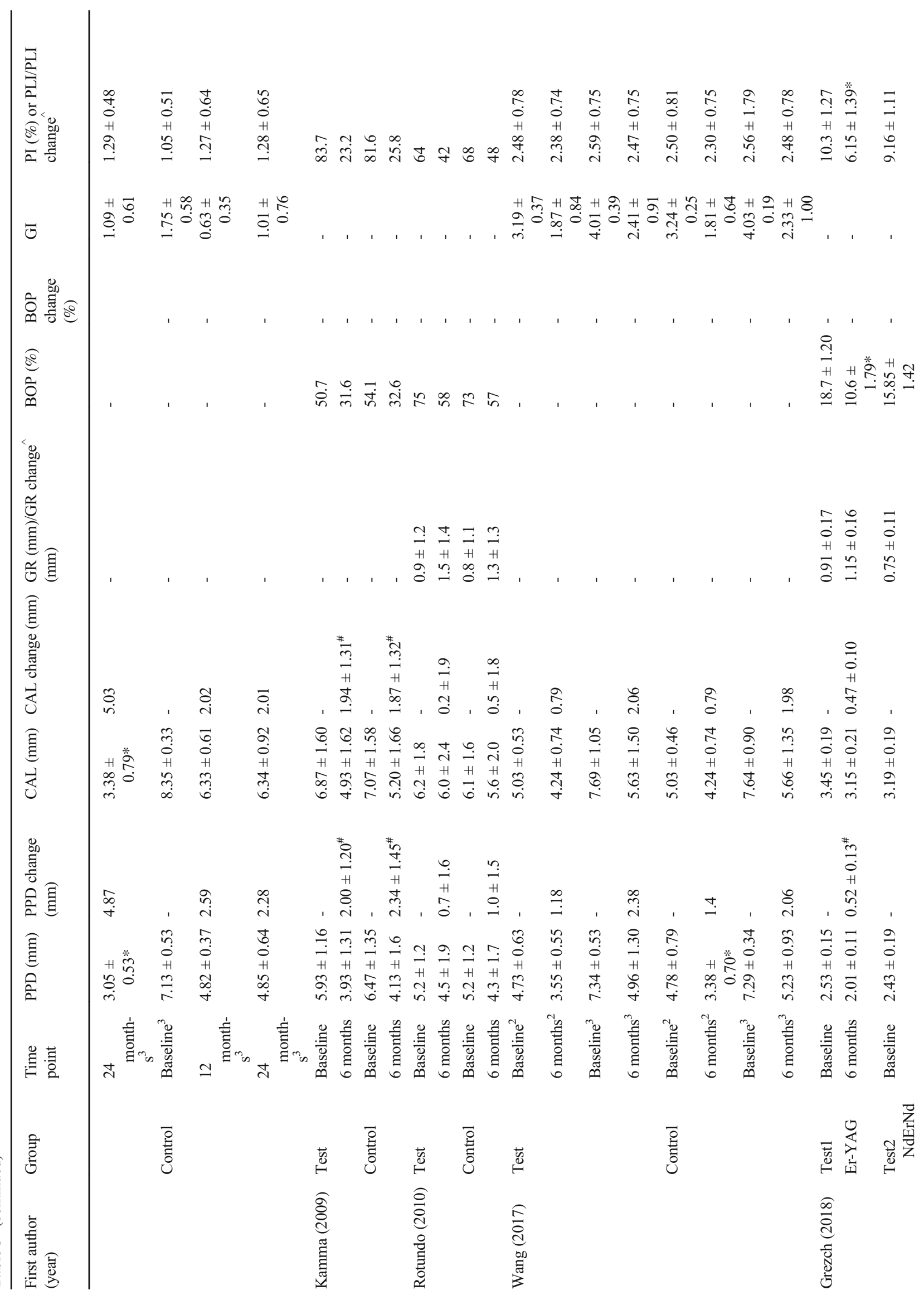


biomarker levels/volumes were reported in only 1 article respectively [60], and no significant difference could be found between the treatment modalities at 6 months. For mean changes in subgingival biofilm composition, 4 studies reported relevant results $[54,55,58,60,61]$. Two studies failed to distinguish any difference from microorganisms in the periodontal pockets between Er:YAG laser and SRP groups 6 months, 1 year, and 2 years after treatment $[54,55,58]$. In one study, laser therapy yielded statistically significantly lower total bacterial loads (TBL) at 6 months compared with conventional SRP treatment [61]. On the contrary, the detection rate of Porphyromonas gingivalis $(P g)$ in the Er:YAG laser group at 6 months was higher than in SRP group in one study [60].

\section{Quality assessment}

The assessment of risk of bias of the included studies is illustrated in Table 5 and was based on the Cochrane Center and CONSORT guidelines (Consolidated Standards of Reporting Trials) to evaluate the quality of RCTs [21, 63].

\section{Discussion}

The aim of the present systematic review was to investigate the effects of laser application as monotherapy of at least 20 patients with untreated periodontitis after a follow-up of 6 months and to compare them with nonsurgical mechanical instrumentation alone. It should be noted that studies reporting on adjunctive laser application to conventional mechanical instrumentation procedures and studies conducted in treated periodontitis patients and in patients enrolled in supportive periodontal therapy were not considered for the present systematic review. The results indicated that in untreated periodontitis patients, laser monotherapy failed to yield superior clinical benefits compared with non-surgical mechanical instrumentation alone.

The purpose of using laser for periodontal therapy is based on the premise that lasers are effective for subgingival calculus removal $[13,64]$, for reduction of inflammatory mediators including interleukin (IL)- $1 \beta$ or tumor necrosis factor (TNF)- $\alpha$ [65], and for reduction of subgingival bacterial deposits [66]. On the other hand, the concern of using lasers to treat periodontitis is the potential damage of the root surface, the bone, and the surrounding tissues. Because of its emission wavelength $(2.94 \mu \mathrm{m})$ which is highly absorbed in water and hydroxyapatite and its thermomechanical ablation mechanism, the Er:YAG laser is considered the most effective laser in periodontal treatments [12] removing subgingival 
Study

ID
WMD $(95 \% \mathrm{Cl})$

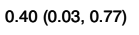

$-0.05(-0.37,0.27)$

$-0.30(-1.14,0.54)$

$-0.13(-0.69,0.43)$

$0.22(0.13,0.31)$

$0.14(-0.04,0.32)$
$\%$

Weight

Rotundo 2010

Wang 2017

Grezch 2018

Overall (I-squared $=36.7 \%, p=0.176$ )

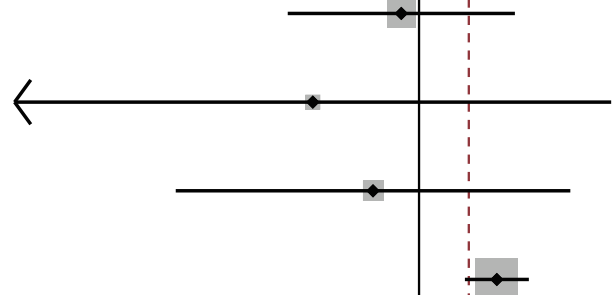

NOTE: Weights are from random effects analysis

Fig. 2 Forest plot of the weighted mean change in PPD at 6 months with laser as monotherapy compared to non-surgical mechanical instrumentation alone

calculus while leading to minimal thermal damage to adjacent periodontal tissues and without affecting the dental pulp [67-69]. Other lasers such as $\mathrm{CO}_{2}$ and $\mathrm{Nd}$ :YAG lasers which are commonly used as high power lasers are not suitable for ablation of hard tissues such as the root surface or the alveolar bone as they carbonize these tissues and exert severe thermal side effects on the target and surrounding tissues [19]. Rather, they are effective for soft tissue surgery. Thermal injury is a major concern when applying laser irradiation. Ablation by means of Er:YAG laser has been reported to induce a temperature rise of less than $6{ }^{\circ} \mathrm{C}$ directly on the root surface and of 0.6-2.2 ${ }^{\circ} \mathrm{C}$ in the pulpal wall [19] which does not cause damage to the pulp. However, one histological study, which compared the effects of the Er:YAG laser instrumentation of diseased root surfaces and mechanical removal of plaque and subgingival calculus with SRP, showed that ablation by means of laser resulted in an increased loss of cementum and roughened tooth surfaces [18]. Compared with laser treatments, Gomez et al. (2009) found ultrasonic instrumentation to better preserve the original morphology and microstructure of root cementum [41]. Concerning bone damage, it has been shown that laser-mediated cutting with an Er:YAG laser preserved the trabecular architecture and the thermal and mechanical damages were minimal and limited to the margins of the cut [70]. By using proper laser tips and selecting ideal energy parameters, possible side effects on the root surfaces caused by the laser irradiation may be reduced [17].

The outcomes of two meta-analyses of the present systematic review revealed an additional benefit of $0.14 \mathrm{~mm}$ PPD change and of $0.08 \mathrm{~mm}$ CAL change in favor of the Er:YAG laser compared with non-surgical instrumentation alone. These results are in line with earlier reviews $[13,71]$ showing that Er:YAG monotherapy yielded similar clinical results as conventional mechanical debridement. Our review complements the existing reviews, however focused on RCTs with a follow-up of at least 6 months and only included studies reporting on clinical data. Both procedures resulted in significant PPD reductions with initially deeper pockets presenting 


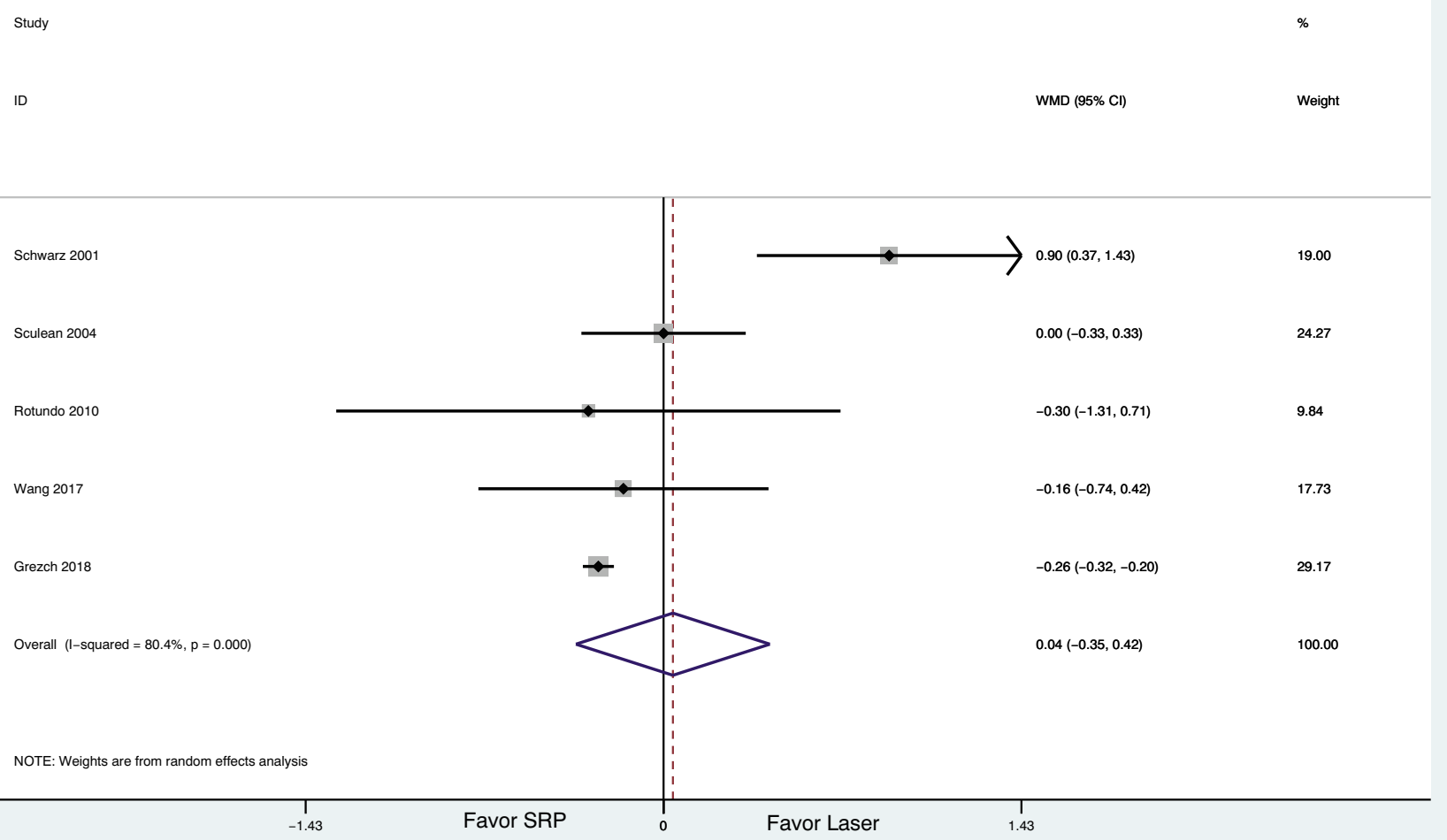

Fig. 3 Forest plot of the weigthed mean change in CAL at 6 months with laser as monotherapy compared to non-surgical mechanical instrumentation alone

the greatest reduction [55]. When correlating probing depths and clinical results, 5 studies looked at initial probing depths. Shallow pockets showed a higher CAL loss when nonsurgical mechanical instrumentation alone was performed compared with laser treatment [61]. For medium and deep pockets, both treatments yielded similar CAL gain [61]. Interestingly, Crespi et al. (2007) and Wang et al. (2017) found a greater benefit for Er:YAG laser in deeper pockets and inaccessible sites compared with non-surgical mechanical instrumentation alone. One of the major limitation of

Table 4 Summary of selected data with laser monotherapy compared with non-surgical mechanical instrumentation alone

\begin{tabular}{|c|c|c|c|c|c|c|c|c|}
\hline Article (year) & $\begin{array}{l}\text { Mean PPD } \\
\text { change }\end{array}$ & $\begin{array}{l}\text { Residual } \\
\text { PPD }\end{array}$ & $\begin{array}{l}\text { Mean CAL } \\
\text { change }\end{array}$ & $\begin{array}{l}\text { Mean } \mathrm{BoP} / \\
\mathrm{BI} \text { change }\end{array}$ & $\begin{array}{l}\text { Mean PI/ } \\
\text { PLI change }\end{array}$ & $\begin{array}{l}\text { Mean changes in subgingival } \\
\text { biofilm composition }\end{array}$ & $\begin{array}{l}\text { Mean changes in GCF } \\
\text { biomarker levels }\end{array}$ & PROMS \\
\hline $\begin{array}{l}\text { Schwarz (2001 } \\
\text { and 2003) }\end{array}$ &,$++*$ &,$++*$ &,$++^{*}$ &,$++*$ & - & - & NR & NR \\
\hline Sculean (2004) & - & NR & - & - & - & NR & NR & NR \\
\hline Crespi (2007) & $+^{*}$ & $+*$ & $+^{*}$ & - & - & NR & NR & NR \\
\hline Kamma (2009) & - & - & - & - & - & NR & NR & NR \\
\hline Rotundo (2010) & - & - & - & - & - & NR & NR & - \\
\hline Wang (2017) & - & $+{ }^{1}$ & - & - & - & + & - & NR \\
\hline Grezch (2018) & - & - & $+{ }^{1}$ & + & + & + & NR & NR \\
\hline $\begin{array}{l}\text { Total } \\
\text { (statistically } \\
\text { significant) }\end{array}$ & 2 & 3 & 3 & 2 & 1 & 4 & $\mathbf{0}$ & $\mathbf{0}$ \\
\hline
\end{tabular}

${ }^{1}$ For shallow sites $(1-3 \mathrm{~mm}) ;{ }^{2}$ for moderately deep sites $(4-6 \mathrm{~mm}) ;{ }^{3}$ for deep sites $(>7 \mathrm{~mm}) ;+$ statistically significant, - statistically not significant, $* 1$ year outcome; 2 -year outcomes, $N R$ not reported, $N A$ not applicable 
Table 5 Parameters to evaluate the quality of randomized controlled trials (RCT) according to the Cochrane Center and CONSORT guidelines
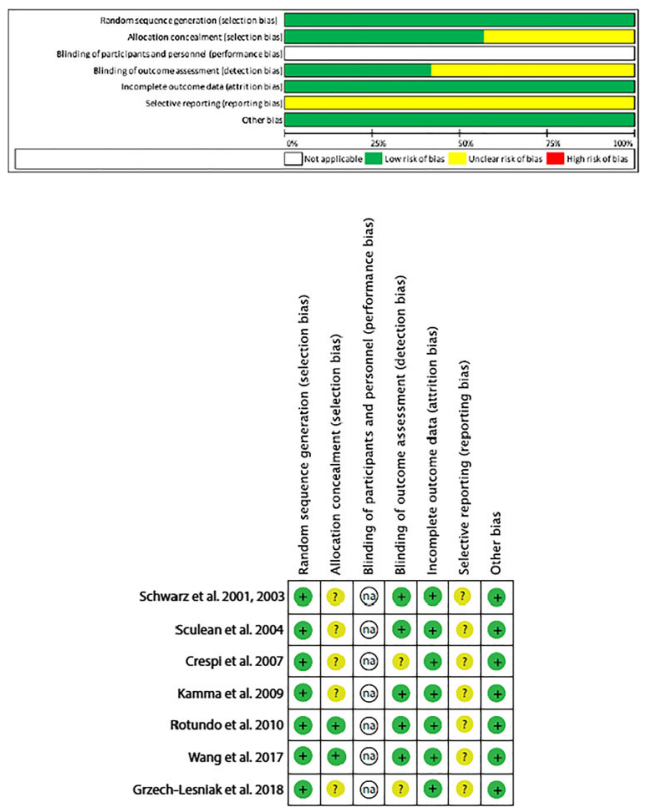

conventional SRP treatment is the difficult access in deep pockets, furcation areas, and root concavities [72]. Rabbani et al. (1981) showed a high correlation between pocket depth and the amount of residual calculus: the deeper the pocket, the more difficult to remove the calculus thoroughly by hand instruments [73]. Conversely, due to the small size of the laser tip, lasers have the advantage of treating otherwise inaccessible areas and sites. Ge et al. (2017) evaluated the clinical use of Er,Cr:YSGG laser in the management of degree II or III furcation involvement, and their results demonstrated that the reduction of PPD and BOP after 6 and 12 months was higher in the laser group than in the conventional root planing group [39].

An early study compared the effectiveness of subgingival calculus removal by Er:YAG laser to hand instrumentation. $83.3 \pm 5.7 \%$ of the root surface was calculus-free after laser irradiation in contrast to $93.9 \pm 3.7 \%$ after SRP with half of the treatment time used for laser therapy [11]. In terms of time efficiency, others reported a lower efficiency for ablation by means of Er:YAG laser when compared with conventional ultrasonic scaling [19]. Also in this study, it was shown that Er:YAG laser-treated surfaces were macroscopically rougher or most similar to ultrasonically scaled roots [19]. In combination with a fluorescent calculus detection system, Er:YAG laser enabled equal or even more effective removal of subgingival calculus and a predictable preservation of root surface structure compared with SRP [74, 75]. The question then arises whether or not Er:YAG laser therapy is an additional tool in conjunction with open flap debridement (OFD)[76]. It should be noted that laser acquisition entails substantial costs, yet data reporting on cost-effectiveness are still missing.

This review has some limitations. First, not many RCTs present data of over 2 years, here only 2 studies [55, 57] report on 2-year data. Second, only one of the included studies reported on residual PPD $>5 \mathrm{~mm}$ although, from a clinical perspective, residual PPD are the main parameter to evaluate therapeutic success and further treatment needs. Third, no study reported on time effectiveness. Fourth, all but one study were carried out in a split-mouth design with possible carry-over effects.

Taken together, within its limitations, currently available evidence indicates that in patients with untreated periodontitis, the single use of Er:YAG laser does not seem to yield clinical advantages over non-surgical mechanical instrumentation alone in terms of PPD and CAL changes.

Acknowledgements Open access funding provided by University of Bern.

Funding This study was supported by the Department of Periodontology, University of Bern.

\section{Compliance with ethical standards}

Conflict of interest The authors declare that they have no conflict of interest.

Ethical approval Not needed for this review.

Informed consent Not applicable to this review.

Open Access This article is licensed under a Creative Commons Attribution 4.0 International License, which permits use, sharing, adaptation, distribution and reproduction in any medium or format, as long as you give appropriate credit to the original author(s) and the source, provide a link to the Creative Commons licence, and indicate if changes were made. The images or other third party material in this article are included in the article's Creative Commons licence, unless indicated otherwise in a credit line to the material. If material is not included in the article's Creative Commons licence and your intended use is not permitted by statutory regulation or exceeds the permitted use, you will need to obtain permission directly from the copyright holder. To view a copy of this licence, visit http://creativecommons.org/licenses/by/4.0/.

\section{References}

1. Ash MMG, Gitlin BN, Smith WA (1964) Correlation between plaque and gingivitis. J Periodontol 35(5):424-429. https://doi. org/10.1902/jop.1964.35.5.424

2. Badersten A, Nilveus R, Egelberg J (1984) Effect of nonsurgical periodontal therapy. II. Severely advanced periodontitis. J Clin Periodontol 11(1):63-76. https://doi.org/10.1111/j.1600-051x. 1984.tb01309.x

3. Badersten A, Nilveus R, Egelberg J (1984) Effect of nonsurgical periodontal therapy. III. Single versus repeated instrumentation. J Clin Periodontol 11(2):114-124. https://doi.org/10.1111/j.1600051x.1984.tb00839.x 
4. Loos B, Kiger R, Egelberg J (1987) An evaluation of basic periodontal therapy using sonic and ultrasonic scalers. J Clin Periodontol 14(1):29-33. https://doi.org/10.1111/j.1600-051x. 1987.tb01509.x

5. Zappa U, Smith B, Simona C, Graf H, Case D, Kim W (1991) Root substance removal by scaling and root planing. J Periodontol 62(12):750-754. https://doi.org/10.1902/jop.1991.62.12.750

6. Polson AM, Frederick GT, Ladenheim S, Hanes PJ (1984) The production of a root surface smear layer by instrumentation and its removal by citric acid. J Periodontol 55(8):443-446. https:// doi.org/10.1902/jop.1984.55.8.443

7. Kinersly T, Jarabak JP, Phatak NM, Dement J (1965) Laser effects on tissue and materials related to dentistry. J Am Dent Assoc 70: 593-600. https://doi.org/10.14219/jada.archive.1965.0268

8. Morlock BJ, Pippin DJ, Cobb CM, Killoy WJ, Rapley JW (1992) The effect of Nd:YAG laser exposure on root surfaces when used as an adjunct to root planing: an in vitro study. J Periodontol 63(7): 637-641. https://doi.org/10.1902/jop.1992.63.7.637

9. Gaspirc B, Skaleric U (2001) Morphology, chemical structure and diffusion processes of root surface after Er:YAG and Nd:YAG laser irradiation. J Clin Periodontol 28(6):508-516. https://doi.org/10. 1034/j.1600-051x.2001.028006508.x

10. Niemz MH (1996) Laser-tissue interactions: fundamentals and applications. Springerverlag, Berlin

11. Eberhard J, Ehlers H, Falk W, Acil Y, Albers HK, Jepsen S (2003) Efficacy of subgingival calculus removal with Er:YAG laser compared to mechanical debridement: an in situ study. J Clin Periodontol 30(6):511-518. https://doi.org/10.1034/j.1600-051x. 2003.00052.x

12. Aoki A, Ando Y, Watanabe H, Ishikawa I (1994) In vitro studies on laser scaling of subgingival calculus with an erbium:YAG laser. J Periodontol 65(12):1097-1106. https://doi.org/10.1902/jop.1994. 65.12.1097

13. Schwarz F, Aoki A, Becker J, Sculean A (2008) Laser application in non-surgical periodontal therapy: a systematic review. J Clin Periodontol 35(8 Suppl):29-44. https://doi.org/10.1111/j.1600051X.2008.01259.x

14. Koort H FM (1995) Laser effects on dental hard tissue. In: Miserendino, Pick R, eds Lasers in Dentistry. Chicago, Quintessence Publishing Co, Inc. 57-70

15. Seka WD FJ, Fried JDB, Fried D, Visuri SR, Walsch JT (1996) Laser ablation of dental hard tissue: from explosive ablation to plasma-mediated ablation. Proc SPIE 2672, Lasers in Dentistry II 2672. https://doi.org/10.1117/12.238763

16. Agoob Alfergany M, Nasher R, Gutknecht N (2019) Calculus removal and root surface Roughness When Using the Er:YAG or Er, Cr:YSGG Laser Compared with Conventional instrumentation method: a literature review. Photobiomodul Photomed Laser Surg 37(4):197-226. https://doi.org/10.1089/photob.2018.4465

17. Crespi R, Barone A, Covani U (2006) Er:YAG laser scaling of diseased root surfaces: a histologic study. J Periodontol 77(2): 218-222. https://doi.org/10.1902/jop.2006.050043

18. Frentzen M, Braun A, Aniol D (2002) Er:YAG laser scaling of diseased root surfaces. J Periodontol 73(5):524-530. https://doi. org/10.1902/jop.2002.73.5.524

19. Aoki A, Miura M, Akiyama F, Nakagawa N, Tanaka J, Oda S, Watanabe H, Ishikawa I (2000) In vitro evaluation of Er:YAG laser scaling of subgingival calculus in comparison with ultrasonic scaling. J Periodontal Res 35(5):266-277. https://doi.org/10.1034/j. 1600-0765.2000.035005266.x

20. Salvi GE, Stahli A, Schmidt JC, Ramseier CA, Sculean A, Walter C (2020) Adjunctive laser or antimicrobial photodynamic therapy to non-surgical mechanical instrumentation in patients with untreated periodontitis: a systematic review and meta-analysis. J Clin Periodontol 47(Suppl 22):176-198. https://doi.org/10.1111/jcpe. 13236
21. Moher D, Liberati A, Tetzlaff J, Altman DG, Group P (2010) Preferred reporting items for systematic reviews and meta-analyses: the PRISMA statement. Int J Surg 8(5):336-341. https://doi.org/10. 1016/j.ijsu.2010.02.007

22. Moher D, Liberati A, Tetzlaff J, Altman DG, Group P (2009) Preferred reporting items for systematic reviews and meta-analyses: the PRISMA statement. J Clin Epidemiol 62(10):1006-1012. https://doi.org/10.1016/j.jclinepi.2009.06.005

23. Moher D, Shamseer L, Clarke M, Ghersi D, Liberati A, Petticrew M, Shekelle P, Stewart LA, Group P-P (2015) Preferred reporting items for systematic review and meta-analysis protocols (PRISMA-P) 2015 statement. Syst Rev 4:1. https://doi.org/10.1186/2046-40534-1

24. Calkins CC, Platt K, Potempa J, Travis J (1998) Inactivation of tumor necrosis factor-alpha by proteinases (gingipains) from the periodontal pathogen, Porphyromonas gingivalis. Implications of immune evasion. J Biol Chem 273(12):6611-6614. https://doi. org/10.1074/jbc.273.12.6611

25. Stone PW (2002) Popping the (PICO) question in research and evidence-based practice. Appl Nurs Res 15(3):197-198. https:// doi.org/10.1053/apnr.2002.34181

26. Higgins J, Thomas J (2019) Cochrane handbook for systematic reviews of interventions. (6)

27. Higgins JP, Thompson SG, Deeks JJ, Altman DG (2003) Measuring inconsistency in meta-analyses. BMJ 327(7414):557560. https://doi.org/10.1136/bmj.327.7414.557

28. Alzoman HA, Diab HM (2016) Effect of gallium aluminium arsenide diode laser therapy on Porphyromonas gingivalis in chronic periodontitis: a randomized controlled trial. Int J Dent Hyg 14(4): 261-266. https://doi.org/10.1111/idh.12169

29. Ambrosini P, Miller N, Briancon S, Gallina S, Penaud J (2005) Clinical and microbiological evaluation of the effectiveness of the Nd:Yap laser for the initial treatment of adult periodontitis. A randomized controlled study. J Clin Periodontol 32(6):670-676. https://doi.org/10.1111/j.1600-051X.2005.00738.x

30. Amid R, Gholami GA, Mojahedi M, Aghalou M, Gholami M, Mirakhori M (2017) Effects of root debridement with hand curettes and Er:YAG laser on chemical properties and ultrastructure of periodontally-diseased root surfaces using spectroscopy and scanning electron microscopy. J Lasers Med Sci 8(2):66-71. https://doi. org/10.15171/jlms.2017.12

31. Andersen R, Loebel N, Hammond D, Wilson M (2007) Treatment of periodontal disease by photodisinfection compared to scaling and root planing. J Clin Dent 18(2):34-38

32. Badran Z, Boutigny H, Struillou X, Weiss P, Laboux O, Soueidan A (2012) Clinical outcomes after nonsurgical periodontal therapy with an Er:YAG laser device: a randomized controlled pilot study. Photomed Laser Surg 30(7):347-353. https://doi.org/10.1089/pho. 2011.3215

33. Bocher S, Wenzler JS, Falk W, Braun A (2019) Comparison of different laser-based photochemical systems for periodontal treatment. Photodiagn Photodyn Ther 27:433-439. https://doi.org/10. 1016/j.pdpdt.2019.06.009

34. Castro Dos Santos N, Andere N, Miguel MMV, Dos Santos LM, Santamaria M Jr, Mathias IF, Jardini MAN, Santamaria MP (2019) Photobiomodulation for the treatment of periodontal pockets in patients with type 2 diabetes: 1 -year results of a randomized clinical trial. Lasers Med Sci 34(9):1897-1904. https://doi.org/10.1007/ s10103-019-02799-0

35. Ciurescu CE, Cosgarea R, Ciurescu D, Gheorghiu A, Popa D, Franzen R, Arweiler NB, Sculean A, Gutknecht N (2019) Adjunctive use of InGaAsP and Er,Cr:YSGG lasers in nonsurgical periodontal therapy: a randomized controlled clinical study. Quintessence Int 50(6):436-447. https://doi.org/10.3290/j.qi. a42508 
36. Derdilopoulou FV, Nonhoff J, Neumann K, Kielbassa AM (2007) Microbiological findings after periodontal therapy using curettes, Er:YAG laser, sonic, and ultrasonic scalers. J Clin Periodontol 34(7):588-598. https://doi.org/10.1111/j.1600-051X.2007.01093.x

37. Everett JD, Rossmann JA, Kerns DG, Al-Hashimi I (2017) Laser assisted non-surgical periodontal therapy: a double blind, randomized clinical trial. Open Dent J 11:79-90. https://doi.org/10.2174/ 1874210601711010079

38. Foroutan T, Amid R, Karimi MR (2013) Comparison of manual tools, ultrasonic and erbium-doped yttrium aluminum garnet (Er: YAG) laser on the debridement effect of the surface of the root of teeth suffering from periodontitis. J Lasers Med Sci 4(4):199-205

39. Ge L, Zhang Y, Shu R (2017) Er,Cr:YSGG Laser application for the treatment of periodontal furcation involvements. Photomed Laser Surg 35(2):92-97. https://doi.org/10.1089/pho.2016.4145

40. Giannelli M, Bani D, Viti C, Tani A, Lorenzini L, Zecchi-Orlandini S, Formigli L (2012) Comparative evaluation of the effects of different photoablative laser irradiation protocols on the gingiva of periodontopathic patients. Photomed Laser Surg 30(4):222-230. https://doi.org/10.1089/pho.2011.3172

41. Gomez C, Bisheimer M, Costela A, Garcia-Moreno I, Garcia A, Garcia JA (2009) Evaluation of the effects of Er:YAG and Nd:YAG lasers and ultrasonic instrumentation on root surfaces. Photomed Laser Surg 27(1):43-48. https://doi.org/10.1089/pho.2008.2236

42. Harmouche L, Courval A, Mathieu A, Petit C, Huck O, Severac F, Davideau JL (2019) Impact of tooth-related factors on photodynamic therapy effectiveness during active periodontal therapy: a 6-months split-mouth randomized clinical trial. Photodiagn Photodyn Ther 27:167-172. https://doi.org/10.1016/j.pdpdt.2019. 05.022

43. Jensen J, Lulic M, Heitz-Mayfield LJ, Joss A, Lang NP (2010) Nd: YAG (1064 nm) laser for the treatment of chronic periodontitis: a pilot study. J Investig Clin Dent 1(1):16-22. https://doi.org/10. 1111/j.2041-1626.2010.00009.x

44. Krohn-Dale I, Boe OE, Enersen M, Leknes KN (2012) Er:YAG laser in the treatment of periodontal sites with recurring chronic inflammation: a 12-month randomized, controlled clinical trial. J Clin Periodontol 39(8):745-752. https://doi.org/10.1111/j.1600051X.2012.01912.x

45. Lopes BM, Marcantonio RA, Thompson GM, Neves LH, Theodoro LH (2008) Short-term clinical and immunologic effects of scaling and root planing with Er:YAG laser in chronic periodontitis. J Periodontol 79(7):1158-1167. https://doi.org/10.1902/jop. 2008.070600

46. Malali E, Kadir T, Noyan U (2012) Er:YAG lasers versus ultrasonic and hand instruments in periodontal therapy: clinical parameters, intracrevicular micro-organism and leukocyte counts. Photomed Laser Surg 30(9):543-550. https://doi.org/10.1089/pho.2011.3202

47. Miyazaki A, Yamaguchi T, Nishikata J, Okuda K, Suda S, Orima K, Kobayashi T, Yamazaki K, Yoshikawa E, Yoshie H (2003) Effects of Nd:YAG and CO2 laser treatment and ultrasonic scaling on periodontal pockets of chronic periodontitis patients. $\mathrm{J}$ Periodontol 74(2):175-180. https://doi.org/10.1902/jop.2003.74.2. 175

48. Moritz A, Gutknecht N, Doertbudak O, Goharkhay K, Schoop U, Schauer P, Sperr W (1997) Bacterial reduction in periodontal pockets through irradiation with a diode laser: a pilot study. J Clin Laser Med Surg 15(1):33-37. https://doi.org/10.1089/clm.1997.15. 33

49. Moritz A, Schoop U, Goharkhay K, Schauer P, Doertbudak O, Wernisch J, Sperr W (1998) Treatment of periodontal pockets with a diode laser. Lasers Surg Med 22(5):302-311. https://doi.org/10. 1002/(sici)1096-9101(1998)22:5<302::aid-1sm7>3.0.co;2-t

50. Noro Filho GA, Casarin RC, Casati MZ, Giovani EM (2012) PDT in non-surgical treatment of periodontitis in HIV patients: a split- mouth, randomized clinical trial. Lasers Surg Med 44(4):296-302. https://doi.org/10.1002/lsm.22016

51. Saglam M, Koseoglu S, Tasdemir I, Erbak Yilmaz H, Savran L, Sutcu R (2017) Combined application of Er:YAG and Nd:YAG lasers in treatment of chronic periodontitis. A split-mouth, singleblind, randomized controlled trial. J Periodontal Res 52(5):853862. https://doi.org/10.1111/jre.12454

52. Soo L, Leichter JW, Windle J, Monteith B, Williams SM, Seymour GJ, Cullinan MP (2012) A comparison of Er:YAG laser and mechanical debridement for the non-surgical treatment of chronic periodontitis: a randomized, prospective clinical study. J Clin Periodontol 39(6):537-545. https://doi.org/10.1111/j.1600-051X. 2012.01873.x

53. Yilmaz S, Kuru B, Kuru L, Noyan U, Argun D, Kadir T (2002) Effect of gallium arsenide diode laser on human periodontal disease: a microbiological and clinical study. Lasers Surg Med 30(1): 60-66. https://doi.org/10.1002/1sm.10010

54. Schwarz F, Sculean A, Georg T, Reich E (2001) Periodontal treatment with an Er: YAG laser compared to scaling and root planing. A controlled clinical study. J Periodontol 72(3):361-367. https:// doi.org/10.1902/jop.2001.72.3.361

55. Schwarz F, Sculean A, Berakdar M, Georg T, Reich E, Becker J (2003) Periodontal treatment with an Er:YAG laser or scaling and root planing. A 2-year follow-up split-mouth study. J Periodontol 74(5):590-596. https://doi.org/10.1902/jop.2003.74.5.590

56. Sculean A, Schwarz F, Berakdar M, Romanos GE, Arweiler NB, Becker J (2004) Periodontal treatment with an Er:YAG laser compared to ultrasonic instrumentation: a pilot study. J Periodontol 75(7):966-973. https://doi.org/10.1902/jop.2004.75.7.966

57. Crespi R, Cappare P, Toscanelli I, Gherlone E, Romanos GE (2007) Effects of Er:YAG laser compared to ultrasonic scaler in periodontal treatment: a 2-year follow-up split-mouth clinical study. J Periodontol 78(7):1195-1200. https://doi.org/10.1902/jop.2007. 060460

58. Kamma JJ, Vasdekis VG, Romanos GE (2009) The effect of diode laser $(980 \mathrm{~nm})$ treatment on aggressive periodontitis: evaluation of microbial and clinical parameters. Photomed Laser Surg 27(1):1119. https://doi.org/10.1089/pho.2007.2233

59. Rotundo R, Nieri M, Cairo F, Franceschi D, Mervelt J, Bonaccini D, Esposito M, Pini-Prato G (2010) Lack of adjunctive benefit of Er:YAG laser in non-surgical periodontal treatment: a randomized split-mouth clinical trial. J Clin Periodontol 37(6):526-533. https:// doi.org/10.1111/j.1600-051X.2010.01560.x

60. Wang Y, Li W, Shi L, Zhang F, Zheng S (2017) Comparison of clinical parameters, microbiological effects and calprotectin counts in gingival crevicular fluid between Er: YAG laser and conventional periodontal therapies: A split-mouth, single-blinded, randomized controlled trial. Medicine (Baltimore) 96(51):e9367. https://doi.org/ 10.1097/MD.0000000000009367

61. Grzech-Lesniak K, Sculean A, Gaspirc B (2018) Laser reduction of specific microorganisms in the periodontal pocket using Er:YAG and Nd:YAG lasers: a ramdomized controlled clinical study. Lasers Med Sci 33(7):1461-1470. https://doi.org/10.1007/s10103-0182491-z

62. Robinson PJ (1975) Possible roles of diseased cementum in periodontitis. J Prev Dent 2(3):3-5

63. Schulz KF, Altman DG, Moher D (2010) CONSORT 2010 statement: updated guidelines for reporting parallel group randomised trials. J Pharmacol Pharmacother 1(2):100-107. https://doi.org/10. 4103/0976-500X.72352

64. Ishikawa I, Aoki A, Takasaki AA (2008) Clinical application of erbium:YAG laser in periodontology. J Int Acad Periodontol 10(1):22-30

65. Dominguez A, Gomez C, Garcia-Kass AI, Garcia-Nunez JA (2010) IL-1beta, TNF-alpha, total antioxidative status and microbiological findings in chronic periodontitis treated with fluorescence- 
controlled Er:YAG laser radiation. Lasers Surg Med 42(1):24-31. https://doi.org/10.1002/lsm.20873

66. Low SB, Mott A (2014) Laser technology to manage periodontal disease: a valid concept? J Evid Based Dent Pract 14(Suppl):154159. https://doi.org/10.1016/j.jebdp.2014.03.010

67. Belal MH, Watanabe H (2014) Comparative study on morphologic changes and cell attachment of periodontitis-affected root surfaces following conditioning with $\mathrm{CO} 2$ and Er:YAG laser irradiations. Photomed Laser Surg 32(10):553-560. https://doi.org/10.1089/ pho.2014.3769

68. Kilinc E, Roshkind DM, Antonson SA, Antonson DE, Hardigan PC, Siegel SC, Thomas JW (2009) Thermal safety of Er:YAG and Er,Cr:YSGG lasers in hard tissue removal. Photomed Laser Surg 27(4):565-570. https://doi.org/10.1089/pho.2008.2335

69. Monteiro L, Delgado ML, Garcês F, Machado M, Ferreira F, Martins M, Salazar F, Pacheco JJ (2019) A histological evaluation of the surgical margins from human oral fibrousepithelial lesions excised with $\mathrm{CO} 2$ laser, Diode laser, Er: YAG laser, Nd:YAG laser, electrosurgical scalpel and cold scalpel. Med Oral Patol Oral Cir Bucal 24(2):e271-e280. https://doi.org/10.4317/medoral.22819

70. Zeitouni J, Clough B, Zeitouni S, Saleem M, Al Aisami K, Gregory C (2017) The effects of the Er:YAG laser on trabecular bone microarchitecture: comparison with conventional dental drilling by micro-computed tomographic and histological techniques. F1000Res 6:1133. https://doi.org/10.12688/f1000research.12018.1

71. Zhao Y, Yin Y, Tao L, Nie P, Tang Y, Zhu M (2014) Er:YAG laser versus scaling and root planing as alternative or adjuvant for chronic periodontitis treatment: a systematic review. J Clin Periodontol 41(11):1069-1079. https://doi.org/10.1111/jcpe.12304

72. Cobb CM (1996) Non-surgical pocket therapy: mechanical. Ann Periodontol 1(1):443-490. https://doi.org/10.1902/annals.1996.1.1. 443

73. Rabbani GM, Ash MM Jr, Caffesse RG (1981) The effectiveness of subgingival scaling and root planing in calculus removal. J Periodontol 52(3):119-123. https://doi.org/10.1902/jop.1981.52.3.119

74. Schwarz F, Bieling K, Venghaus S, Sculean A, Jepsen S, Becker J (2006) Influence of fluorescence-controlled Er:YAG laser radiation, the Vector system and hand instruments on periodontally diseased root surfaces in vivo. J Clin Periodontol 33(3):200-208. https://doi.org/10.1111/j.1600-051X.2005.00889.x

75. Schwarz F, Sculean A, Berakdar M, Szathmari L, Georg T, Becker $\mathrm{J}$ (2003) In vivo and in vitro effects of an Er:YAG laser, a GaAlAs diode laser, and scaling and root planing on periodontally diseased root surfaces: a comparative histologic study. Lasers Surg Med 32(5):359-366. https://doi.org/10.1002/1sm.10179

76. Sculean A, Schwarz F, Berakdar M, Windisch P, Arweiler NB, Romanos GE (2004) Healing of intrabony defects following surgical treatment with or without an Er:YAG laser. J Clin Periodontol 31(8):604-608. https://doi.org/10.1111/j.1600-051X.2004.00525.x

Publisher's note Springer Nature remains neutral with regard to jurisdictional claims in published maps and institutional affiliations. 